\title{
DISSENT
}

\section{Traditional public health injury control does not apply to violence}

\author{
Les Fisher
}

Violence is ancient. It is much more complex than just injury control or public health practice. In Genesis, Cain's "grandchildren" found that Bronze Age weapons were a more efficient means of inflicting violent harm than their hands.

Which injury control practices can really make a difference in reducing juvenile violence morbidity and mortality? When I first began working in this area in 1964, the field had just begun to transfer its preventive thrust to more safely designed childhood consumer products. The "human factors" approach, reminding everyone to be more "careful" had failed. Instead, my efforts focused on the products themselves (toys, flammable nightwear, playground equipment, car safety seats, household toxic substances, etc). At the time, I thought injury control had all the answers and concluded that its paradigm was suitable not only to non-intentional but also to intentional injury. ${ }^{1-3}$

However, by 1985, my ideas about the causes and possible control of adolescent suicides, many of which were related to firearms or to sexual experimentation with inhalants, had changed. They included some controversial applied biochemical research suggesting that levels of biomines found in the brain, such as serotonin, might increase aggression and the risk of violence. It seemed it might even be possible to determine high risk individuals by this means. ${ }^{4}$ By 1993 , several studies showed that "serotonin deficiencies are associated with alcoholic predisposition among people characterized by depression, poor impulse control, heightened self- and otherdirected aggression...". For youth homicides (and some suicides) it appeared there was little nexus of drug, firearm violence, and injury, except for indirect coincidental drug trafficking wars among youth gangs. ${ }^{6}$

Injury control and epidemiological research to reduce firearm related intentional injuries by making handguns less available and safer are now at the cutting edge. Nevertheless, injury control is only part of the whole; diverse technical, political factors, and the "thunder of history" overlay our potential successes in using the injury control paradigm to reduce intentional injuries.

\section{Technical overlays}

Haddon built on earlier work to adapt the energy exchange model of injury causes and to formulate control strategies. ${ }^{7}$ Certainly, energy gone wrong is the culprit; but the compounding variables (not just risks) in youth violence may also relate to combinations of endogenous drugs (for example serotonin levels in cerebral spinal fluid, and exogenous drugs, such as alcohol). There is a further overlay of aggression, self esteem, economic depression, and an inability to constructively communicate with others and ourselves. Haddon's strategies applied to violence are far from safety caps, flame retardant clothing, etc. Nor do they involve just limiting the accessibility or safety design of handguns.

His work suggests a need for: (a) screening for high risk social, economic, biological, or psychological risks and stresses; (b) finding ways to increase self esteem, to cope with frustrations and negative emotions by supportive counseling; (c) positive parental supports; (d) use of prescription drug and counseling therapies; (e) effective poison control center systems, emergency "hotlines", or emergency department protocols; and ( $f$ ) rehabilitation of offenders. ${ }^{4}$ Indeed, the control of violence is so overlaid by behavioral factors (psychological, social, and biochemical) that expertise in psychology and psychiatry is essential. An angry young adult or older child will probably be able to bypass a safety locked trigger on a handgun and older guns will be available for some time. The firearm today is one of the weakest links in the chain of control. Moreover, little scientific evidence is yet available that these interventions work, and for safety locks, there are no uniform standards to assure they will all perform effectively.

\section{Political realities}

In the US, the political realities are that the juvenile violence control manifests itself in the more publicly recognized, better supported, and better funded juvenile justice systems. This is probably true in other nations. Another political reality is that diverse disciplines continue to maintain their own viewpoint rather than partner with others. ${ }^{8}$ Although there are several newly developed partnerships between public health and the criminal justice 
system, these are not extensive. We can only hope that mandated government interagency practices or executive office requirements will further such approaches. Personalized safety latches on police weapons are promising but remain to be developed for general public use. Moreover, interest groups in America, such as the National Rife Association, continue to succeed politically in limiting government's public health responses to firearms injury reduction. They have succeeded in blocking bills tied to Centers for Disease Control appropriations. In injury control practice, as well as politics and history, the perception of reality is as important as the reality.

Nevertheless, we are at the threshold of change in juvenile violence control. The progress we made in the safety of medicines, automobiles, and consumer products should permit us to learn. We should not permit these successful histories to be revised by opponents. ${ }^{9}$ We need to be clear about how we made headway in earlier times.

\section{Other historical realities}

The childhood injury control field has had a poor scientific record of assessing and responding to the psychological and social causes in the prevention of injury. We focused at great waste on the "accident prone child " and only found out by the 1970s that our Gestalt was too narrow. The "accident" prone person is also a product of immediate economic, social and domestic pressures, as well as complex psychopathology originating in early life. ${ }^{10}$ Our current focus on teaching conflict resolution skills in schools is likely to be effective only if implemented with other initiatives that target the broader effects of poverty. ${ }^{11}$

Yes, violence is as old as Noah's ark, Cain and Abel, and the Tower of Babel. Its causes and control remain impinged in our ability to effectively understand, communicate intentions, and interact with our fellows, and to cope with our own and other's emotions. We have done well with public health models. These have proven useful (and in the long run of injury control history, may continue to make a difference). ${ }^{11-14}$ But their transfer to intentional injury applications are still nascent, theoretical (perhaps even philosophical), and largely untested. As the first century Redactor of Pirki Avos wrote: "You are not required to complete the task, yet you are not free to withdraw from it".

These views do not necessarily reflect those of the American Public Health Association nor Injury Control and Emergency Public Health Association

1 Fisher L. Childhood injuries-causes. Preventive theories and case studies: an overview on the role of the sanitarian and other health professionals. Fournal of Environmental Health $1988 ; 2: 123-6$.

2 Fisher L, Van Buren J, Lawrence R, et al. Genesee Region Poison Prevention Project: phase II. Vet Human Toxicol Poison Preve

3 Final report of the Poison Control Center Advisory Workgroup. Report to the National Center for Injury Prevention and Control and the Maternal and Child Health Bureau. 1996:32.

4 Fisher L. The governor of New York State's Final Report from the Youth Suicide Prevention Council. Some frontiers for public health consideration of etiological research and prevention of intentional injuries. Presented at the American Public Health Association annual meeting. New Orleans, 22 Oct 1987

5 Pihl RO, Peterson JB. Alcohol, serotonin, and aggression. Alcohol Health and Research World. Special Focus: Alcohol, Aggression and Injury. National Institutes of Health, 1993;17:115.

6 Howell, JC. Youth gangs: an overview. fuvenile justice bulletin. Washington, DC: US Department of Justice. Office of Justice Program, Office of Juvenile Justice and Delinquency tice Program, Office of

7 Hrevention, August 1998. f Public Health 1970;60:2229-34.

F Public Health 1970;60:2229-34.
8 Kushner HI. Self destruction in the promised land, a psycholculKushner HI. Self destruction in the promised land, a psycholcul-
tural biology of American suicide. New Brunswick, NJ: Rutgers University Press, 1989: 63-90.

9 Fisher L. The driver's role in automobile safety. Am f Public Health 1997;87:871-2.

10 Weinerman ER. Accident proneness: a critique. Am f Public Health 1949;39:1527-30.

11 Durkin MS, Kuhn L, Davidson LL, et al. Epidemiology and prevention of severe assault and gun injuries to children in an urban community. F Trauma 1996;41:667-73.

12 Bonnie, RJ, Fulco CE, Liverman, CT, eds. Reducing the burden of injury: advancing prevention and treatment. Committee on Injury Prevention and Control. Division of Health Promotion and Disease Research. Institute of Medicine, Com-
mittee on Injury Prevention and Control. Washington, DC: mittee on Injury Prevention and

13 Sherman LW, Gottfredson D, MacKenzie D, et al. Preventing crime: what works, what doesn't, what's promising. A report to the United States Congress. Washington, DC: National Institute of Justice, Feb 1997 .

14 Rivara, FR. Grossman DC. Prevention of traumatic deaths to children in the United States : how far have we come and where do we need to go? Pediatrics 1996; 97:791-7. 